\title{
EVALUATION OF IMMUNOMODULATORY ACTIVITY OF SESBANIA GRANDIFLORA FLOWERS EXTRACT IN MICE
}

\author{
(n) \\ Bansal College of Pharmacy, \\ Bhopal, M.P, India 462021 \\ Submitted: $28-01-2013$ \\ Revised: 20-01-2014 \\ Accepted: 05-03-2014 \\ *corresponding author \\ Mallik Arunabha \\ Email: \\ mallikpharmacology@ \\ gmail.com
}

\author{
Mallik Arunabha*, Nayak Satish
}

\begin{abstract}
The aim of the present study was to investigate the immunomodulatory activity of Sesbania grandiflora on cellular and humoral immunity. Oral administration of the methanolic extract (200 and $400 \mathrm{mg} / \mathrm{kg}$ ) of S. grandiflora flowers, in mice, dosedependently significantly enhanced the production of circulating antibody titre in mice in response to SRBC. It significantly potentiated the delayed-type hypersensitivity reaction induced by sheep red blood cells (SRBC). Good response was also found towards phagocytosis in carbon clearance assay and prevented myelosuppression in cyclophosphamide drug. Aqueous extract at $250 \mathrm{mg} / \mathrm{kg}$ dose level failed to show immunomodulatory activity but $500 \mathrm{mg} / \mathrm{kg}$ of aqueous extract potentiated the activity however less significantly compared with both dose of methanolic extract. The results obtained in this study indicate that methanolic extract $(400 \mathrm{mg} / \mathrm{kg})$ of $S$. grandiflora possesses potential immunomodulatory activity.
\end{abstract}

Keywords: Immunomodulator, Sesbania grandiflora, Humoral immune responses, Delayed type hypersensitivity reaction, Phagocytosis

\section{INTRODUCTION}

A number of plants reputed in traditional Indian medicine literature to promote physical and mental health, improve defence mechanisms of the body and enhance longevity. The use of medicinal plant products as immunomodulators as possible therapeutic benefit is becoming a new subject of scientific investigators (Patwardhan et al., 1990). Medicinal plants used for immunomodulation can provide potential alternatives to conventional chemotherapies for a variety of diseases, especially when the host defence mechanism has to be activated under the conditions of impaired immune response. The use of plant products in the indigenous system of medicines as immunomodulators indeed can modulate the body's immune system, as a variety of plant derivatives such as polysaccharides, lectins, peptides, flavonoids and tannins have been reported to modulate the immune system in various in vivo models (Shivaprasad et al., 2006).

S. grandiflora L. pers (Fabaceae) commonly known as "sesbania" and "agathi," is widely used in Indian traditional medicine for the treatment of a broad spectrum of diseases including leprosy, gout, rheumatism, tumor and liver disorders (Sreelatha et al., 2011). All parts of $S$. grandiflora are utilized for medicine in South eastern Asia and India including preparations derived from the roots, bark, gum, leaves, flowers, and fruit. The juices of the flowers have a special ability to improve vision and the crushed leaves are applied to sprains and bruises of all kinds. A tea made from the leaves is believed to have antibiotic, anthelmintic, antitumor and contraceptive properties (Doddola et al., 2008). The bark is considered as a tonic and an antipyretic, and a remedy for gastric troubles and diabetes. The principal medicinal effects are due to the tree's astringency; hence it is used against inflammation, venom and other poisons, bacterial infections and tumour (Burbidage, 1965).

However, so far no systematic study has examined the as immunomodulatory activity in the flowers of this plant. Hence, the present study based on the ethno medical claims, was sought to evaluate the scientific validity for the immunomodulators activity of the methanolic and aqueous extract of $S$. grandiflora flowers. 


\section{MATERIALS AND METHODS}

The flowers of $S$. grandiflora were collected from Bhopal District, Madhya Pradesh, India. Further taxonomic identification was conducted by the Prof. Madhuri Modak, Botanised, Department of Botany, M.V.M. College, Bhopal, Madhya Pradesh, India. A voucher specimen voucher specimens (Specimen No. MVM/BOT/HEB/ $11 / \mathrm{SG}-23)$ were kept at the Department of Botany.

\section{Preparation of the extract}

The powdered drug was taken and subjected for successive solvent extraction. The extraction was carried out for $18 \mathrm{hrs}$ with the following solvents with a ratio $1: 4 \mathrm{w} / \mathrm{v}$, in the increasing order of the polarity i.e. Petroleum ether $\left(60-80^{\circ} \mathrm{C}\right)$, chloroform, methanol and water.

\section{Drugs}

Accurately weighed quantities of the methanolic and aqueous extracts were suspended in $1 \%$ sodium carboxy methylcellulose (SCMC) to prepare suitable forms of the dosages.

\section{Preliminary phytochemical screening}

To identify the essential constituents of the methanolic and aqueous extract of $S$. grandiflora flowers such as alkaloids, terpenes and steroids, saponins, flavonoids, polysaccharides and tannins, a preliminary phytochemical screening was carried out using various test methods of Draggendorff's and Mayer's test, Liebermann-Burchard test, foam formation test, lead acetate test, Molish's and Fehling's test and ferric chloride test. (Trease and Evans, 1983).

\section{Selection and maintenance of animals}

Swiss albino mice (DRDO, Gwalior, India) weighing between 20 to $30 \mathrm{~g}$ of either sex were used. Animals were housed under standard conditions of temperature, $12 \mathrm{~h} / 12 \mathrm{~h}$ light/dark cycle and fed with standard pellet diet and tap water. All the experiments were approved and conducted as per the guidelines of Institutional Animal Ethical Committee.

\section{Preparation of SRBC suspension}

The blood was collected from a healthy sheep from the local slaughterhouse in Alsever's solution, Bhopal, India. It was preserved at a temperature of $2-8^{\circ} \mathrm{C}$. On the day of immunization, the blood sample was centrifuged at $5000 \mathrm{rpm}$ for $10 \mathrm{~min}$ and then washed three times to remove plasma with $0.9 \%$ sodium chloride solution. The SRBC $(20 \% \mathrm{v} / \mathrm{v})$ suspension was then prepared in $0.9 \%$ sodium chloride solution.

\section{Preparation of Alsever's solution (Thakur et al., 2006) \\ Formula of Alsever's Solution is Citric} acid $0.055 \mathrm{~g}$, Sodium citrate $0.8 \mathrm{~g}$, Glucose $2.05 \mathrm{~g}$, Sodium chloride $0.42 \mathrm{~g}$, Distilled water to make volume up to $100 \mathrm{~mL}$

\section{Acute toxicity study in mice}

Healthy female albino mice weighing 25$30 \mathrm{~g}$, maintained under controlled conditions of temperature $\left(20-25^{\circ} \mathrm{C}\right)$ and humidity $(55 \%)$ were used for toxicity study as per the internationally accepted protocol drawn under the OECD guidelines 423. The over night fasted animals were administered orally at the dose level of $2000 \mathrm{mg} / \mathrm{kg}$ BW by gastric intubation and were observed for toxic symptoms such as behavioural change, locomotion, convulsion and mortality for 48h. Based on the study the doses were selected for the evaluation of immunomodulator activity.

\section{Immunomodulatory protocols} SRBC specific humoral immune responses

The mice were divided into 5 groups, each consisting of 6 animals. Group I: Recived $1 \mathrm{~mL} 1 \%$ SCMC for 14 days; Group II-III: Received methanolic extract at dose 200 and $400 \mathrm{mg} / \mathrm{kg} / \mathrm{BW}$ respectively for 14 days; Group IV-V: Administered aqueous extract at dose 250 and $500 \mathrm{mg} / \mathrm{kg}$ BW for 14 days.

The animals were immunized by injecting $0.1 \mathrm{~mL}$ of $20 \%$ of fresh sheep red blood cells suspension intraperitoneally on day 0 . Seven days later they were challenged by injecting $20 \mu \mathrm{L}$ of SRBC suspension. The estimation of circulating antibody titres was done using standard haemaglutination test. 
Blood samples were collected in micro centrifuge tubes from individual animals by retro-orbital plexus on $D A Y 7$ for primary antibody titer and for secondary antibody titer on $D A Y 15$. Serum was separated and briefly equal volumes of individual serum samples of each group were pooled. Two fold dilutions of pooled serum samples were made in $25 \mu \mathrm{L}$ volumes of normal saline in a micro titration plate to which were added $25 \mu \mathrm{L}$ of $1 \%$ suspension of SRBC in saline. After mixing, the plates were incubated at room temperature for $1 \mathrm{~h}$ and examined for haemaggltination titer. The reciprocal of the highest dilution of the test serum giving agglutination was taken as the antibody titer. The mean titer values of the drug and test extracts treated groups were compared of the control (Sensitized) (Satnam Singh et al., 2012, Shinde et al., 1999).

\section{SRBC -induced delayed type hypersen- sitivity reaction}

The mice were divided into 5 groups, each consisting of 6 animals. Group I: Received $1 \mathrm{~mL} 1 \%$ SCMC for 14 days; Group II-III: Administered methanolic extract at dose 200 and $400 \mathrm{mg} / \mathrm{kg} / \mathrm{BW}$ respectively for 14 days; Group IV-V: Administered aqueous extract at dose 250 and $500 \mathrm{mg} / \mathrm{kg} \mathrm{BW}$ for 14 days.

The mice were primed with injecting $20 \mu \mathrm{L}$ of SRBC suspension intraperitoneally, on day 7 and challenged on day 14 with same amount of SRBC suspension intradermally in the right hind foot pad. The contra lateral paw received equal volume of saline, served as control. The thickness of the foot pad was measured at $24 \mathrm{~h}$ after challenge using speromicrometer (Gokhale et al., 2002).

\section{Phagocytic response}

The mice were divided into 5(five) groups, each consisting of 6 animals. Group I: Recieved $1 \mathrm{~mL} 1 \%$ SCMC for 5 days; Group IIIII: Administered methanolic extract at dose 200 and $400 \mathrm{mg} / \mathrm{kg} / \mathrm{BW}$. respectively for 5 days; Group IV-V:Administered aqueous extract at dose 250 and $500 \mathrm{mg} / \mathrm{kg} \mathrm{BW}$ for 5 days.

At the end of five days, after $48 \mathrm{~h}$, mice were injected via tail vein with carbon ink suspension $(10 \mu \mathrm{L} / \mathrm{g} \mathrm{BW})$.Blood samples were drawn (in EDTA solution, $5 \mu \mathrm{L}$ ) from the retro orbital vein at 0 and $15 \mathrm{~min}$.; a $25 \mu \mathrm{L}$ sample was mixed with $0.1 \%$ sodium carbonate solution $(2 \mathrm{~mL})$ and its optical density was measured at $680 \mathrm{~nm}$. The phagocytic index $(\mathrm{K})$ was calculated using the equation: $\mathrm{K}=(\log \mathrm{OD} 1-\log \mathrm{OD} 2) / 15$ where OD1 and OD2 are optical densities at 0 and 15min respectively (Shruti et al., 2009).

\section{Cyclophosphamide-induced myelosupp- ression}

The mice were divided into 6 groups, each consisting of 6 animals. Group I: Received $1 \mathrm{~mL}$ 1\% SCMC for 13 days; Group II: Were given cyclophosphamide $(30 \mathrm{mg} / \mathrm{kg}$ BW) for 11-13 days. Group II-III: Administered methanolic extract at dose 200 and $400 \mathrm{mg} / \mathrm{kg} /$ BW respectively for 13 days; Group IV-V: Administered aqueous extract at dose 250 and $500 \mathrm{mg} / \mathrm{kg}$ BW for 13 days.

On 11th, 12th and 13th day, all the animals of each group except control were given cyclophosphamide ( $30 \mathrm{mg} / \mathrm{kg}$ i.p.), one hour after administration of extract. On 14th day blood samples were then withdrawn from retro-orbital plexus lysed in sodium carbonate solution from all the groups and total leucocytes count was determined (Dhumal et al., 2013).

\section{Statistical analysis}

Data were expressed as standard error of the means (S.E.M) of and statistical analysis was carried out employing one-way ANOVA followed by Dunnett test, which compares the test groups with the control groups.

\section{RESULTS AND DISCUSSION Phytochemical screening}

The preliminary phytochemical screening of $S$. grandiflora flowers revealed the presence of alkaloids, saponins, terpenoids, phenolics, flavonoids and polysaccharides as essential phytochemical constituents of the methanolic and aqueous flowers extract. Result of preliminary phytochemical screening of various extract of $S$. grandiflora flowers is shown in table I

\section{Acute toxicity study}

The $\mathrm{LD}_{50}$ of methanolic and aqueous extract of $S$. grandiflora flowers was determined. Since no mortality was observed at 2000 and $5000 \mathrm{mg} / \mathrm{kg}$ respectively. 
Table I. Result of preliminary phytochemical screening.

\begin{tabular}{lccccc}
\hline \multicolumn{1}{c}{ Extract } & Flavonoids & Tannins & Alkaloids & Amino Acid & Steroids \\
\hline Petroleum ether & - & - & - & - & + \\
Chloroform & - & - & - & - & + \\
Methanol & +++ & ++ & + & ++ & - \\
Water & ++ & + & + & + & - \\
\hline
\end{tabular}

-: Absent, +: Trace amounts ++: Present, +++: High

Table II. Effect of Sesbania grandiflora flowers on Phagocytic index.

\begin{tabular}{ccccc}
\hline S.No & Group & Dose $\mathbf{~ m g} / \mathbf{k g}$ BW) & Phagocytic index & \% Change \\
\hline 1 & Control & $1 \% \mathrm{SCMC}$ & $0.062 \pm 0.002$ & \\
2 & MESG & $200 \mathrm{mg} / \mathrm{kg}$ & $0.080 \pm 0.002^{* *}$ & $29.03 \uparrow$ \\
3 & MESG & $400 \mathrm{mg} / \mathrm{kg}$ & $0.091 \pm 0.003^{* *}$ & $46.77 \uparrow$ \\
4 & AESG & $250 \mathrm{mg} / \mathrm{kg}$ & $0.069 \pm 0.002^{\mathrm{ns}}$ & $11.30 \uparrow$ \\
5 & AESG & $500 \mathrm{mg} / \mathrm{kg}$ & $0.072 \pm 0.001^{*}$ & $16.13 \uparrow$ \\
\hline
\end{tabular}

Statistical analysis was carried out employing the ANOVA followed by Dunnett test *: $P<0.05, * *: P<0.01$ comparing with the control;

Table III. Effect of Sesbania grandiflora flowers on cyclophosphamide-induced myelosuppression.

\begin{tabular}{cccc}
\hline S.No & Group & Dose $\mathbf{( m g} / \mathbf{k g ~ B W})$ & Total WBC count ${\text { per } \mathbf{~ m m}^{\mathbf{3}}}$ \\
\hline 1 & Control & & $7501.83 \pm 65.36$ \\
2 & Cyclophosphamide & $30 \mathrm{mg} / \mathrm{kg}$ & $3575.17 \pm 55.47$ \\
3 & MESG & $200 \mathrm{mg} / \mathrm{kg}$ & $5329.17 \pm 81.30^{* *}$ \\
4 & MESG & $400 \mathrm{mg} / \mathrm{kg}$ & $6128.67 \pm 49.74^{* *}$ \\
5 & AESG & $250 \mathrm{mg} / \mathrm{kg}$ & $3747.33 \pm 32.41^{\mathrm{ns}}$ \\
6 & AESG & $500 \mathrm{mg} / \mathrm{kg}$ & $3816.00 \pm 58.91^{*}$ \\
\hline
\end{tabular}

Statistical analysis was carried out employing the ANOVA followed by Dunnett test. ${ }^{*}$ : $<<0.05$, **: $\mathrm{P}<0.01$ comparing with the control;

\section{Effect of S. grandiflora on in- vivo SRBC specific humoral immune responses}

Methanolic and aqueous extract of $S$. grandiflora flowers on primary and secondary antibody response on $\mathrm{H}$ A titre are shown in figure 1. In Contrast with control the methanolic and aqueous extract of $S$. grandiflora increase in the primary and secondary antibody formation as dose dependently. Higher dose of methanolic extract $(400 \mathrm{mg} / \mathrm{kg} \mathrm{BW})$ produced maximum enhance with $234.67 \pm 21.33$ and $298.67 \pm 42.68$ primary and secondary antibody formation. Aqueous extract does not show significant augment (apart from $500 \mathrm{mg} / \mathrm{kg}$ ) in primary and secondary antibody titre. The increase in primary and secondary antibody titre was higher with methanolic extract as compared to aqueous extract. The production of secondary antibodies was more prominent as compare to the primary antibodies.

Antibody molecules, a product of $\mathrm{B}$ lymphocytes and plasma cells, are vital to humoral immune responses. $\operatorname{IgG}$ and $\operatorname{IgM}$ are the major immunoglobulins which are involved in the complement activation, opsonization, neutralization of toxins, etc. It is evidenced by increase in the antibody titre in mice, indicated the enhanced responsiveness of B lymphocyte subsets, involved in the antibody synthesis by the augmentation of the humoral immune response to SRBCs by $S$. grandiflora (Yadav et al., 2011, Gautama et al., 2009). 


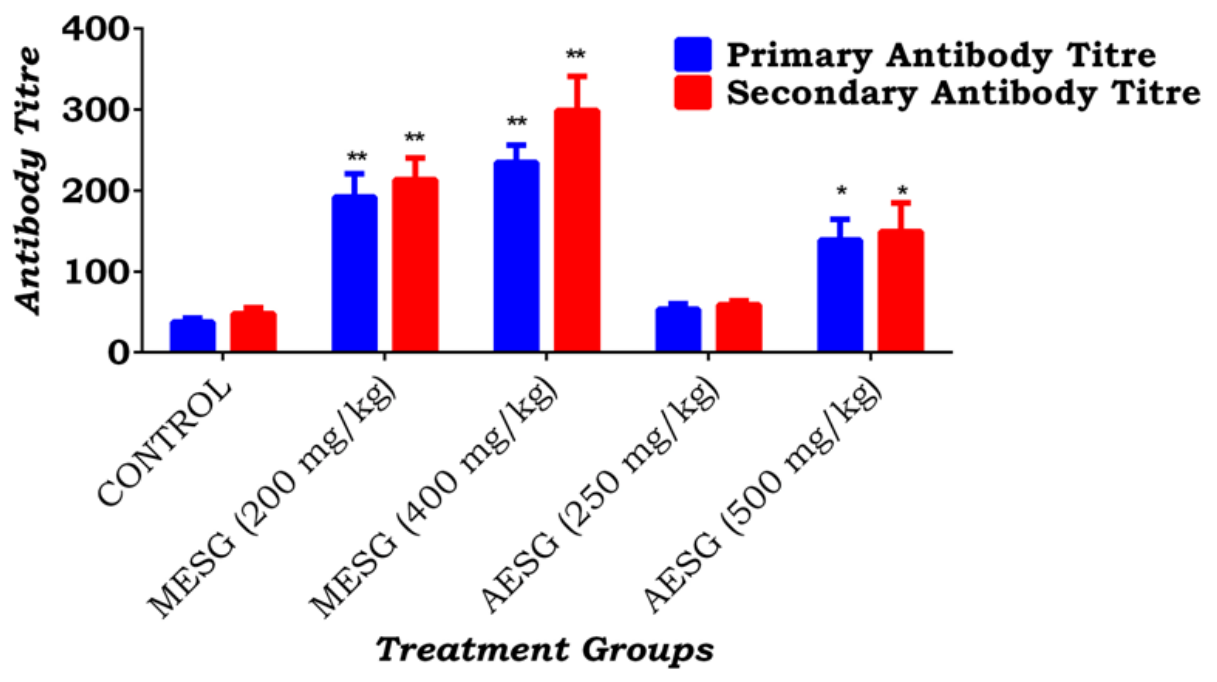

Figure. 1 Effect of Sesbania grandiflora on in- vivo SRBC specific humoral immune responses. Statistical analysis was carried out employing the ANOVA followed by Dunnett test $*:<0.05, * *: \mathrm{P}<0.01$ comparing with the control;

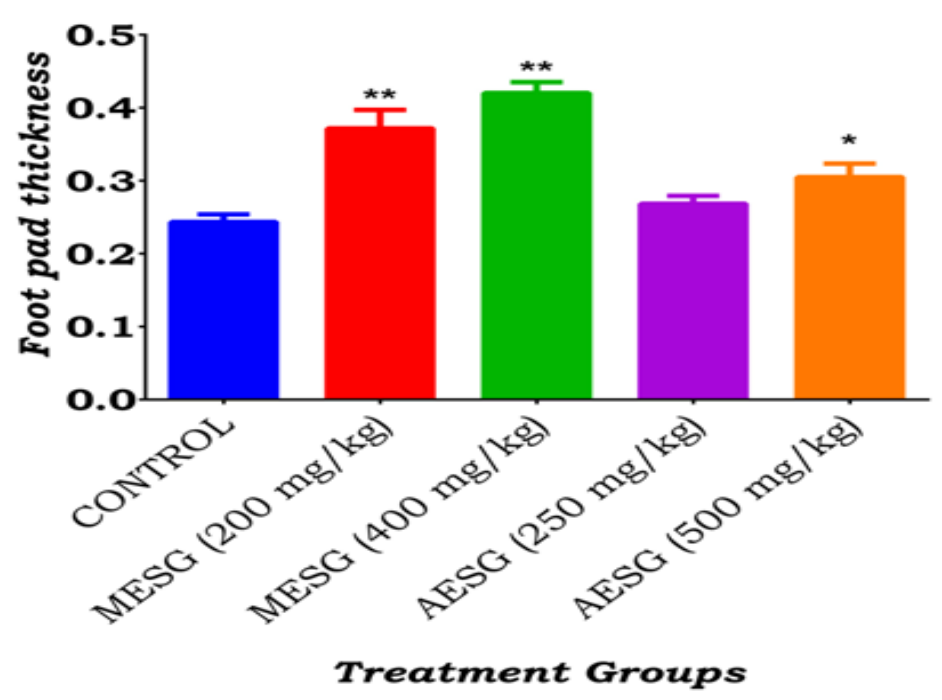

Figure 2. Effect of Sesbania grandiflora on in-vivo SRBC -induced delayed type hypersensitivity reaction. Statistical analysis was carried out employing the ANOVA followed by Dunnett test *: $\mathrm{P}<0.05, * *: \mathrm{P}<0.01$ comparing with the control;

Effect of S. grandiflora on in-vivo SRBC -induced delayed type hypersensitivity reaction

Methanolic and aqueous extract of $S$. grandiflora flowers on delayed type of hypersensitive activity is shown in figure 2 . Methanolic extract of $S$. grandiflora with the dose of 200 and $400 \mathrm{mg} / \mathrm{kg}$ increased paw volume as dose dependent manner after $24 \mathrm{hrs,}$ foot pad thickness in these group were increased by $54.16 \%$ and $75 \%$ i.e. Most significantly $(p<0.01)$ enhanced the delayed type of hypersensitive activity as compared to control (Sensitized) were observed at $24 \mathrm{~h}$ after SRBC injection in the footpad.

Whereas at dose $500 \mathrm{mg} / \mathrm{kg} \quad \mathrm{BW}$, aqueous extract of $S$. grandiflora increased in food pad thickness after $24 \mathrm{~h}$ but at the dose $250 \mathrm{mg} / \mathrm{kg} \mathrm{BW}$ dose not show any significant 
result. Cell-mediated immunity (CMI) involves effectors mechanisms carried out by $\mathrm{T}$ lymphocytes and their products (lymphokines). CMI responses are critical to defense against infectious organisms, infection of foreign grafts, tumor immunity and delayed-type hypersensitivity reactions. Therefore, increase in DTH reaction in mice in response to $\mathrm{T}$ cell dependent antigen revealed the stimulatory effect of methanolic flowers extract of $S$. grandiflora on T cells (Bafna and Mishra., 2004).

\section{Effect of $S$. grandiflora on in vivo phagocytosis}

The faster removal of carbon particles has been correlated with the enhanced phagocytic activity. The phagocytic activity of the eticulo-endothelium system was measured by the removal of carbon particles from the blood circulation (Miller, 1991).

Methanolic and aqueous extract of S. grandiflora flowers on phagocytic activity is shown in table II. Both dose 200 and $400 \mathrm{mg} / \mathrm{kg}$ BW methanolic extract of S. grandiflora significantly increased phagocytic activity as dose dependent manner. These group were increased by $29.03 \%$ and $46.77 \%$ i.e. Most significantly $(p<0.01)$ enhanced the activity as compared to control. Whereas at dose $500 \mathrm{mg} / \mathrm{kg} \mathrm{BW}$, aqueous extract of S. grandiflora less significantly $(\mathrm{p}<0.05)$ increased phagocytic activity by $16.13 \%$ as compared to control.

Effect of $S$. grandiflora on cyclophosphamide-induced myelosuppression

Methanolic and aqueous extract of S. grandiflora on cyclophosphamide-induced myelosuppression is shown in table III. Cyclophosphamide at the dose of $30 \mathrm{mg} / \mathrm{kg}$, i.p. caused a major reduction in the WBCs count. Combined treatment of cyclophosphamide and methanolic extract of $S$. grandiflora (200 and $400 \mathrm{mg} / \mathrm{kg}$ ) resulted in a restoration of bone marrow activity as compared with cyclophosphamide treatment alone with $5329.17 \pm 81.30$ and 6128.67 \pm 49.74 , but aqueous extracts $250 \mathrm{mg} / \mathrm{kg}$ does not show significant result in white blood cell count with cyclophosphamide treat group. Administration of the methanolic extract of $S$. grandiflora flowers was found to increase the total WBC count compare to aqueous extract which was lowered by cyclophosphamide, a cytotoxic drug, indicating that the test drug can stimulate the bone marrow activity (Damre et al., 2003).

\section{CONCLUSION}

The present investigation suggests that methanolic extract derived from S. grandiflora flowers not only potentiates nonspecific immune response, but also improves humoral as well as cell-mediated immunity effectively. The effectiveness of extract can be explored for its medical utilization in treatment of immunodeficiency diseases, cancer and as combinational therapy with antibiotics. Administration of $\mathrm{S}$. in human is simple as its seeds are used as common dietary constituents in Indian household. Its reported immunomodulatory effects warrant further investigation for its use in the cases of clinical immunosupression.

\section{ACKNOWLEDGEMENT}

The authors wish to thank Bansal College of Pharmacy, Bhopal, INDIA for supporting research work.

\section{REFERENCES}

Bafna AR, Mishra SH., 2004. Immunomodulatory Activity of Methanol Extract of Flower-Heads of Sphaeranthus indicus Linn. Ars. Pharm. 45: 281-291.

Burbidage NT., 1965. Australian species of S. scop (leguminosae). Aus. J. Botany 13: 103-141.

Damre AS, Gokhale AB, Phadke AS, Kulkarni, KR, Saraf M 2003. Studies on the immunomodulatory activity of flavonoidal fraction of Tephrosia purpurea. Fitoterapia, 749: 257-260.

Dhumal JS., Yele SU., Ghodekar SN. 2013. Evaluation of immunomodulatory activity of Vigna mungo (L) hepper. J Pharm Phytother, 2: 9-14.

Doddola S., Pasupulati H., Koganti B., Prasad KV., 2008. Evaluation of S. grandiflora for antiurolithiatic and antioxidant properties. J Nat. Med. 62: 300-307.

Gautama G., Sahaa S., Banib S., Kaulb A., Mishraa S., Patil D., et al. 2009. Immunomodulatory activity of Asparagus 
racemosus on systemic Th1/Th2immunity: implications for immunoadjuvant potential. J. Ethnopharmacol; 121: 241-247.

Gokhale AB, Damre AS., Saraf MN. 2003. Investigations into the immunomodulatory activity of Argyreia speciosa. J. Ethnopharmacology 84: 109-114.

Miller LE., 1991. In: Ludke, H.R., Peacock, J.E., Tomar, R.H. (Eds.), Manual of Laboratory Immunology. Lea and Febiger, London, pp. 1-18.

Patwardhan B., Kalbagh D., Patki PS., Nagsampagi BA., 1990. Search of immunomodulatory agents: a review. Indian Drugs. 28: 56-63.

Satnam S., Yadav CPS., Malleshappa NN., 2012. Asian Pac J. Trop. Biomed; 2(6): 433437.

Shinde UA., Phadke AS., Nair AM., Mungantiwar AA., Dikshit VJ., Saraf MN., 1999. Preliminary studies on the immunomodulatory activity of Cedrus deodara wood oil, Fitoterapia. 70: 333-339.

Shivaprasad HN., Kharya MD., Rana AC., Mohan S., 2006. Preliminary immunomodulatory activities of aqueous extract of Terminalia chebula. Pharmaceutical Biology. 44: 32-34.

Shukla S., Mehta A., Johna J., Mehtaa P., et al. 2009. Immunomodulatory activities of the ethanolic extract of Caesalpinia bonducella seeds. J. Ethnopharmacology 125: 252-256.

Sreelatha S., Padma PR., Umasankari E. 2011. Evaluation of anticancer activity of ethanol extract of $S$. grandiflora (Agati Sesban) against Ehrlich ascites carcinoma in Swiss albino mice. $J$ Ethnopharmacol; 134: 984-987.

Thakur M., Bhargava S., Dixit VK., 2006 Immunomodulatory activity of Chlorophytum borivilianum Sant., eCAM

Trease GE., Evans MC., 1983. Textbook of Pharmacognosy, 12th ed. Balliere, Tindall, London, pp. 343-383.

Yadav R., Kharya DM., Yadav N., Savadi R. 2011. Immunomodulatory potential of ethanol extract of Spilanthus acmella leaves Int. J. Biol. Med. Res; 2(3): 631-635 